\title{
O AVANÇO URBANÍSTICO E O DESENVOLVIMENTO SUSTENTÁVEL PARA A GARANTIA DO DIREITO À MORADIA
}

\section{THE URBANISTIC ADVANCEMENT AND SUSTAINABLE DEVELOPMENT FOR THE GUARANTEE OF THE RIGHT TO DWELL}

\author{
${ }^{1}$ Juliana Cardoso Ribeiro Bastos \\ ${ }^{2}$ Ricardo Cotrim Chaccur
}

\section{RESUMO}

A partir da natural convivência entre os homens, com o seu instinto de agrupamento, torna-se relevante pensar nas formas de planejamento do desenvolvimento das cidades. Nesse sentido, o direito urbanístico destaca-se ao apresentar as normas que direcionam esse caminho, sendo indispensável um olhar sustentável desse desenvolvimento. Contudo, dar-se-á especial relevância ao direito à moradia, como um direito humano e fundamental que faz parte do núcleo de proteção da dignidade do ser humano. Dessa forma, a relação entre estes elementos tão importantes para uma vida em sociedade e, em específico, os problemas que acometem o desenvolvimento da cidade de São Paulo.

Palavras Chave: Direitos Fundamentais, Urbanismo, Moradia, Desenvolvimento Sustentável, Constituição Federal de 1988

\begin{abstract}
As living together is part of human beings with the basic instinct of grouping themselves together, it's relevant to elaborate city development plans. In this sense the urbanistic rights stands out showing the rules that direct this way not neglecting how indispensable is sustainability aspects in the development. However it will be given a special relevance in home rights as a human right and is a fundamental part of the core protection of human dignity. In this way the relationship of these key important elements for a life in society and specifically the problems that affects the development of São Paulo's city.
\end{abstract}

Key Words: Fundamental Rights, Urbanism, Housing, Sustainable Development, Federal Constitution of 1988

\footnotetext{
${ }^{1}$ Mestre em Direito Constitucional pela Pontifícia Universidade Católica - PUC, São Paulo (Brasil). Professora de Direito Constitucional pela Pontifícia Universidade Católica - PUC, São Paulo (Brasil). E-mail: ju_crbastos@yahoo.com.br

${ }^{2}$ Mestre em Direito Político e Econômico pela Universidade Presbiteriana Mackenzie - Mackenzie, São Paulo (Brasil). Professor de Direito Constitucional e Direitos Fundamentais das Faculdades Metropolitanas Unidas FMU, São Paulo (Brasil). E-mail: rcchaccur.adv@gmail.com
} 


\section{INTRODUÇÃO}

Muitas das cidades apresentam problemas de saúde, de mobilidade, de violência, de inundações, entre outros, que são decorrentes da má organização efetivada pela administração pública. Constata-se uma deficiência quanto à forma de planejar a expansão do espaço das cidades. Assim, o tema “O avanço urbanístico e o desenvolvimento sustentável para a garantia do direito à moradia" pretende destacar a importância de se atentar para o avanço urbanístico com um olhar da sustentabilidade, que possui sérias consequências para a proteção de uma vida sadia.

Nesse sentido, pretende-se analisar pontos essenciais ligadas às questões urbanísticas, em específico, aqueles relacionados ao direito à moradia. Nesse contexto, ressalta-se a garantia do direito à moradia como um direito humano e fundamental, em que sua proteção vai além dos interesses internos de cada Estado.

Com esse objetivo, apontam-se as diretrizes sociais da política urbana voltadas para um desenvolvimento sustentável do espaço urbano, bem como um olhar cuidadoso do Estatuto da Cidade e dos instrumentos da política urbana.

Com a intenção de abordar as questões jurídicas que envolvem o desenvolvimento das cidades sob o prisma da sustentabilidade, será analisada a proteção constitucional do desenvolvimento sustentável e a sua posição de valor constitucional na ordem econômica brasileira para a garantia do Estado do bem-estar social.

Nesse quadro geral, pretende-se, ainda, verificar o processo de urbanização da cidade de São Paulo e os desafios enfrentados a partir da ocupação irregular do solo, assim como suas consequências para a qualidade de vida dos seus habitantes.

A relevância do tema deve-se, sobretudo, à problemática de convergir a atuação do desenvolvimento das cidades com a preservação do meio ambiente como forma de garantir à moradia com dignidade. Isso impõe ao Estado o dever da realização de fins e a execução de tarefas voltadas a preservação do meio ambiente junto às decisões de organização das cidades.

Desta forma, o desafio desse texto científico é salientar a importância do meio ambiente como um dos princípios a nortear o avanço urbanístico, como forma de buscar o desenvolvimento sustentável das cidades capaz de proporcionar o direito à moradia com dignidade. 


\section{LIÇÕES DE DIREITO URBANÍSTICO}

\subsection{Cidade e urbanismo}

Estudar ou tratar das cidades é estudar sobre o urbanismo, uma vez que ambos os conceitos estão relacionados pelo fato de urbanismo estar intimamente ligado à ideia de desenvolvimento de uma cidade. Esta, por sua vez, encerra a ideia de um local de convivência de uma determinada população, composta por comércio, igrejas ou templos religiosos, paço municipal, onde se desenvolvem as atividades administrativas do município, hospitais ou postos de saúde e necessariamente por moradias, locais utilizados pelas pessoas que habitam a cidade para morar e criar a sua família.

As cidades surgem na história da humanidade com o objetivo de criar um polo de integração e convivência de pessoas, que antes viviam de forma isolada, na sua característica mais primitiva e individual. Assim, da necessidade de se organizarem, formaram-se grupos e a união desses grupos se transformaram em uma sociedade, que cada vez mais possuem necessidades e características complexas que exigem do Estado uma maior intervenção e uma prestação positiva para assegurar a convivência pacífica e a paz social.

No Brasil, Carvalho Filho, explica que o sentido da cidade, atualmente, é o resultado da transformação de determinado conglomerado populacional em Município, sendo que este ente federativo já se encontrava consolidado mesmo no período Imperial de nossa história (CARVALHO FILHO, 2013.P.03).

Concomitante ao surgimento das cidades, não menos importante é entender o seu desenvolvimento ao longo da história da humanidade, e a ideia de urbanismo e de urbanização têm por finalidade mensurar o nível de planejamento e desenvolvimento da civilização local daquela sociedade, da cidade em questão, analisando as características que as tornam mais ou menos urbanizadas.

Desenvolvendo a ideia de uma cidade urbanizada, se faz necessário frisar a importância de notar que a proteção ao meio ambiente é um direito fundamental previsto no artigo 225 da Constituição Federal Brasileira e originalmente considerado um dos direitos humanos de $3^{\text {a }}$ dimensão, que possuem como valor o direito à solidariedade ou fraternidade, cuja essência é a proteção e preocupação com o bem estar social e com a coletividade. 
Por esta razão que ao tratar do direito à cidade e do direito urbanístico, na atualidade, se torna impossível de dissociar o direito ao meio ambiente e, consequentemente, do direito à cidade sustentável.

Para o alcance desse direito fundamental, isto é, do direito à cidade sustentável como forma de efetivação dos direitos humanos de terceira dimensão, não se pode ignorar o direito social à moradia, uma vez que este último está intimamente relacionado com o primeiro se notar que a ocupação irregular do solo nas áreas urbanas provoca danos ao meio ambiente e como resultado mediato e imediato problemas de saúde, de mobilidade, de violência e outros que afligem e violam direitos humanos que se relacionam com o bem estar social e a coletividade de seres humanos que habitam uma cidade.

Dessa forma, é imperioso observar que o processo de urbanização brasileiro teve seu início de forma mais intensa na década de 1930, com o chamado êxodo rural ${ }^{3}$, causando um aumento repentino da população urbana em relação à população rural, inclusive, sendo esta última superada pela primeira a partir da década de 1970. Entretanto, este movimento migratório não incentivado diretamente pelo governo ${ }^{4}$, encontrou as cidades brasileiras despreparadas para suportar a demanda dos novos moradores, certo de que esta falta de planejamento e preparo cumulada com a valorização das regiões centrais das cidades pelo mercado imobiliário, protegidas pelas elites locais, culminaram com o deslocamento dessa massa migratória, vindo das áreas rurais, para as áreas periféricas das cidades e a ocupação de áreas de encosta, áreas de mananciais ou de preservação ambiental que por não terem valor para o mercado imobiliário ${ }^{5}$ ficavam mais susceptíveis de serem ocupadas.

Importa, ainda, destacar que o tipo de construção das moradias precárias localizadas nas áreas de favelas e assentamentos irregulares, sem aprovação de projetos pela Prefeitura e, portanto, sem controle algum e sem infraestrutura são caracterizadas por uma construção realizada com fios e cabos sem a instalação adequada, sem captação de água e esgoto

\footnotetext{
${ }^{3}$ Expressão dada ao movimento de migração das áreas rurais para as áreas urbanas, conforme explicado por Ermínia Maricato, em seu artigo "Metrópole, Legislação e Desigualdade”, impulsionada, dentre outros motivos, principalmente pela política de incentivo à industrialização e pela consolidação das leis trabalhistas que contemplavam direitos para o trabalhador urbano, mas não o rural, impulsionando os trabalhadores das áreas rurais a buscarem melhores oportunidades e condições de vida nas cidades brasileiras.

${ }^{4}$ MARICATO ao explicar a intensidade do processo migratório campo-cidade, observa que: "essa grande massa que se instalou nas cidades, o fez por sua própria conta e risco”. (MARICATO, 2003, p. 158)

5 Áreas de encosta, de mananciais ou de proteção ambiental são geralmente desvalorizadas pelo mercado imobiliário, justamente por não serem do interesse de investidores de imóveis, uma vez que consideradas de risco em razão da possibilidade de deslizamentos de terra ou alagamento, ou ainda, porque protegidas pelo Poder Público não conseguem autorização ou aprovação de projetos para a construção de empreendimentos imobiliários.
} 
necessário, tornando-se suscetíveis, em casos de enchentes, incêndios ${ }^{6}$, desmoronamentos e grandes catástrofes.

Certo é que o resultado da ocupação irregular do solo nos centros urbanos das cidades brasileiras causa inúmeros problemas em diversas áreas como a do meio-ambiente, da saúde, educação, transportes, segurança e outros, representando verdadeiros nichos de desenvolvimentos precários e com uma alta concentração demográfica, dificultando a solução dos problemas que afligem os habitantes das grandes cidades brasileiras cotidianamente, numa afronta aos direitos humanos e fundamentais dispostos na nossa Carta Magna.

\subsection{O Direito à Moradia e sua relação com os Direitos Humanos}

O direito à moradia é um direito social e humano, conforme reconhecido pelo art. $6^{\circ}$, caput, da Constituição Federal de 1988 e pela Agenda Habitat, organizada pela Conferência das Nações Unidas sobre Assentamentos Humanos - Habitat II, realizada em Instambul, em 1996.

Importa observar que o planeta Terra atingiu, recentemente, o número de 7,3 Bilhões de habitantes no mundo ${ }^{7}$ e, com esta marca inédita, a questão de onde serão abrigados todos estes novos moradores do planeta Terra, bem como a questão da urbanização e sustentabilidade desses centros urbanos, ganham constantemente espaço nas discussões e na agenda ${ }^{8}$ de todos os países do Globo Terrestre.

$\mathrm{O}$ aumento da população mundial cumulada com a falta de espaços nas principais cidades do mundo e o temor da falta de recursos naturais para todos os residentes do planeta no futuro torna notória a preocupação de que o mundo vive uma crise habitacional e ambiental causado pelas aglomerações desorganizadas em grandes centros urbanos, com destaque para

\footnotetext{
${ }^{6}$ O Portal G1 do Globo noticiou que só em 2016 foram registrados cem incêndios em favelas na cidade de São Paulo até julho de 2016, segundo o Corpo de Bombeiros <http://g1.globo.com/sao-paulo/noticia/2016/07/saopaulo-registra-100-incendios-em-favelas-este-ano-dizem-bombeiros.html.> Acesso em 09.09.2016.

${ }^{7}$ O Portal G1 do Globo noticiou em 2015 que a população global chegou à 7,3 bilhões de pessoas e que a estimativa para 2050 é de aproximadamente 10 bilhões de habitantes em 2050 e 11 bilhões em 2100, segundo uma análise bianual do Instituto Francês de Estudos Demográficos (Ined) publicada em 08 de setembro de 2015. 〈http://g1.globo.com/mundo/noticia/2015/09/populacao-mundial-chegara-aos-10-bilhoes-em-2050segundo-estudo.html> Acesso em 09.09.2016.

${ }^{8}$ O Portal das Nações Unidas no Brasil noticiou que o Programa das Nações Unidas para Assentamentos Humanos (ONU-HABITAT) reuniu especialistas e gestores no dia 29 de agosto de 2016, em Curitiba, para discutir papel do setor privado na urbanização sustentável com o objetivo de melhorar as condições de vida em centros urbanos, o encontro é tido como atividade preparatória para conferência global que acontecerá em outubro de 2016 . < https://nacoesunidas.org/programa-da-onu-discute-em-curitiba-papel-do-setor-privado-na-urbanizacaosustentavel/> Acesso em 09.09.2016.
} 
países em desenvolvimento, como no caso do Brasil, cujo impacto ao meio ambiente é indiscutível.

Nelson Saule, explica que:

\begin{abstract}
$\mathrm{Na}$ Declaração Universal dos Direitos Humanos, o direito à moradia tem a sua origem no artigo XXV, que dispõe sobre o direito a um padrão de vida adequado da seguinte forma: 1 . Toda pessoa tem direito a um padrão de vida capaz de assegurar a si e a sua família saúde e bem estar, alimentação, vestuário, habitação, cuidados médicos e os serviços sociais indispensáveis, direito à segurança em caso de desemprego, doença, invalidez, viuvez, velhice ou outros casos de perda dos meios de subsistência em circunstâncias fora de seu controle.(SAULE JUNIOR, 2004. p.90)
\end{abstract}

Sobre a origem do direito à moradia em nosso ordenamento jurídico, Saule explica que a compreensão deste direito e as suas formas de proteção internacional são decorrentes de um conjunto de normas previstas por diversos instrumentos internacionais de direitos humanos, tendo a sua origem mediata no Pacto Internacional de Direitos Econômicos, Sociais e Culturais e o Pacto Internacional dos Direitos Civis e Políticos, ambos ratificados pelo Brasil ${ }^{9}$ por meio dos Decretos 591 de 6 de julho de 1992 e 592 de 6 de julho de 1992, respectivamente, cujo o artigo 11 do Pacto Internacional de Direitos Econômicos, Sociais e Culturais estabelece que: “Os Estados-partes no presente Pacto reconhecem o direito de toda pessoa a um nível de vida adequado para si próprio e sua família, inclusive à alimentação, vestimenta e moradia adequadas, assim como a uma melhoria contínua de suas condições de vida" ${ }^{\text {" }}$, contendo, assim, tal dispositivo o principal fundamento do reconhecimento do direito à moradia como um direito humano, gerando aos Estados-partes signatários a obrigação legal de promover e proteger esse direito, sendo este um dos principais fundamentos do Estado brasileiro e, portanto, de sua responsabilidade.

Nas palavras de Saule Junior:

O tratamento constitucional sobre o direito à moradia deve ser extraído dos princípios constitucionais das normas estabelecidas sobre os direitos fundamentais, sobre a repartição de competências entre as entidades da Federação Brasileira e sobre a política urbana, no que diz respeito à proteção deste direito nas cidades brasileiras. (SAULE JUNIOR, 2004. p.165)

Contudo, deve-se ressaltar que o direito à moradia é meio para garantir outros direitos sociais e fundamentais ao cidadão, dispostos pela Constituição Pátria, como saúde, segurança, liberdade de locomoção, bem como o direito ao meio ambiente, o que nos remete à uma

\footnotetext{
${ }^{9}$ Existem outras Convenções e Pactos Internacionais ratificados pelo Brasil e que tratam de direitos sociais, dos quais o direito à moradia encontra-se protegido, entretanto, o presente trabalho optou por não abordá-los, uma vez que se pretende, apenas, demonstrar a origem do direito à moradia no nosso ordenamento jurídico.

${ }^{10}$ Artigo 11 do Pacto Internacional dos Direitos Econômicos, Sociais e Culturais de 1966.
} 
preocupação com o desenvolvimento sustentável de uma cidade e, com a consequente melhora do bem-estar dos cidadão, como forma de inclusão social e da garantia de um dos princípios basilares da nossa Constituição, a dignidade da pessoa humana.

É notório que as moradias precárias ${ }^{11}$, geralmente localizadas em áreas ocupadas de forma irregular, como nos casos das favelas, tendem a se caracterizar por inúmeros problemas como alto índice de violência, de epidemias, falta ou difícil acesso ao transporte público descente, dentre outros, que com certeza resultam no cerceamento de outros direitos sociais e fundamentais, excluindo ou afastando a população dessas áreas do exercício pleno de sua cidadania.

Promover a regularização fundiária e a urbanização dessas áreas é uma forma de incluir os cidadãos residentes dessas moradias precárias na cidade legal, assegurando o acesso aos direitos humanos de segunda e terceira dimensões, na qual temos presente o direito ao meio ambiente, à uma qualidade de vida e até mesmo respeitado o princípio da dignidade da pessoa humana, essência de um Estado que preconiza em seu alicerce os direitos humanos como fundamento de sua sociedade, possibilitando que o cidadão tenha a oportunidade de se desenvolver profissionalmente, economicamente e socialmente.

Nesse sentido, Tutikian ao relacionar a importância da regularização fundiária e sua consequente urbanização com a inclusão social, esclarece que: "É importante ressaltar que a legalização da propriedade imobiliária, antes de ser interesse da cidade e condição para o progresso, é uma forma de alavancar a cidadania, de trazer as pessoas que vivem à margem da sociedade para “dentro do sistema.”(TUTIKIAN, 2011, p. 204).

\subsection{Diretrizes Sociais da Política Urbana e o Direito a Cidades Sustentáveis}

Com o objetivo de efetivar o direito social à moradia, bem como a Política Urbana preconizada nos artigos 182 e 183 da atual Constituição Federal Brasileira, o legislador pátrio buscou regulamentar tal direito social por meio da Lei 10.257 de 2001, mais conhecida como o Estatuto da Cidade, na qual trouxe à luz um rol de diretrizes gerais da Política Urbana em seu artigo $2^{\circ}$, dentre os quais, Carvalho Filho, agrupou-as em cinco categorias com base no conteúdo das hipóteses descritas no Estatuto, dividindo-as em: diretrizes governamentais,

\footnotetext{
11 Moradias também conhecidas como subnormais, referem-se àquelas que não possuem infraestrutura e saneamento básico, bem como as localizadas em áreas de risco e cuja construção não seja considerada com a mínima segurança para habitação.
} 
diretrizes sociais, diretrizes econômico-financeiras, diretrizes relativas ao solo urbano e, por fim, diretrizes jurídicas (CARVALHO FILHO, 2013.p.30-31).

Para o presente trabalho, ressaltam-se as diretrizes sociais, definidas por Carvalho Filho como aquelas que traçam ações e estratégias da política urbana que visam beneficiar diretamente a sociedade seja por meio de serviços públicos, bem como instrumentos que permitem a participação democrática das populações em relação ao processo de urbanização, dentre as quais, destaca, ainda, o autor, a necessidade de substituir ou melhorar as comunidades de população de baixa renda, habitualmente radicadas em locais como favelas, assentamentos irregulares, grotas, baixadas, comunidades, vilas e etc (CARVALHO FILHO, 2013.p.44-45).

As diretrizes sociais têm a possibilidade de atacar frontalmente o problema da urbanização e do meio ambiente nas cidades brasileiras, tendo em vista serem direcionadas na tentativa de reversão do processo de favelização e, consequentemente, dos problemas decorrentes dessa ocupação do solo urbano, na qual se encontra previsto o direito a cidades sustentáveis como uma dessas diretrizes, de que trata o Estatuto da Cidade, cuja essência encontra-se definida pela dicotomia entre o desenvolvimento da cidade, isto é, sua urbanização, e o bem estar de seus habitantes, assegurando o direito ao meio ambiente e uma qualidade de vida para todos.

\subsection{O Estatuto da Cidade e os Instrumentos da Política Urbana}

O Estatuto da Cidade estabelece uma série de instrumentos para a efetivação da Política Urbana, relacionando-os no artigo $4^{\circ}$ da Lei, com destaque para o inciso III que dispõe sobre o planejamento municipal, dentre os quais, prevê o Plano Diretor, o parcelamento, uso e ocupação do solo, bem como o Zoneamento Ambiental.

Os instrumentos da Política Urbana trouxeram uma significativa contribuição na tentativa de efetivar o direito social à moradia, sendo o Plano Diretor considerado um instrumento básico e fundamental para o desenvolvimento e expansão urbana de uma cidade e, consequentemente, a realização de uma urbanização planejada e efetiva, competindo exclusivamente ao Município aprová-lo por meio de Lei Municipal desde que observadas as diretrizes gerais de desenvolvimento urbano preconizadas na Lei Federal, cuja competência 
advém do artigo 182 da Constituição Federal, devendo constar aspectos físicos, sociais, econômicos, ambientais e administrativos ${ }^{12}$.

Coube, portanto, a cada Munícipio fazê-lo pelo simples motivo de que cada Município possui necessidades específicas e peculiares que devem ser atendidas de forma individual, o que não seria possível por meio de um Plano Diretor que fosse comum à todos os municípios.

Dentre os aspectos acima relacionados, destacam-se os aspectos sociais e ambientais, nas quais Carvalho Filho (CARVALHO FILHO, 2013. p.340-341) explica que se referem à qualidade de vida dos habitantes e usuários permanentes da cidade, bem como a necessidade de proteger o meio ambiente ao projetar os bens jurídicos sociais e econômicos que pretende proteger.

Dessa maneira, o plano diretor deve conter regras que impulsionem e promovam a urbanização da cidade visando a melhoria na qualidade de vida de seus moradores, por meio da construção de obras que viabilizem, por exemplo, o acesso ao direito social à moradia, sem, contudo, prejudicar o meio ambiente, devendo este ser preservado e integrar a cidade urbanizada, o que nos remete ao conceito da cidade sustentável.

Dentro desse contexto, nota-se que os artigos $2^{\circ}$ e $40^{\circ}$ do Estatuto da Cidade estabelecem o diálogo entre governo municipal e a população na elaboração do Plano Diretor, bem como na fiscalização da execução do mesmo, como forma de cooperação entre o Poder Público e a Iniciativa Privada de modo a atender as necessidades dos habitantes locais por meio de audiências públicas, de forma a garantir uma gestão democrática assinalada pelo legislador do Estatuto.

\section{O DESENVOLVIMENTO SUSTENTÁVEL NA CONSTITUIÇÃO DE 1988}

\subsection{A Constituição Econômica e o Estado do bem-estar social}

A Constituição ao longo da história pode ser identificada como um compromisso liberal, chamada por isso de Constituição liberal, como é o caso da Carta Imperial Brasileira de 1824 e, também, como um compromisso social, neste caso a Constituição é conhecida pelo caráter intervencionista do Estado, como ocorreu com a Constituição Brasileira de 1934.

\footnotetext{
${ }^{12}$ Carvalho Filho, valendo-se da classificação adotada por José Afonso da Silva, e acrescentando à esta classificação, o aspecto ambiental, explica que tal divisão tem apenas fins didáticos, bem como ensina, ainda, que esses aspectos devem ser objeto do Plano Diretor do Município.
} 
A Constituição Econômica aparece com o Estado Social, na intenção de regular a economia e conter os abusos advindos de sua atividade. Foi a Constituição Brasileira de 1934 que trouxe, pela primeira vez, o título "Da Ordem Econômica e Social". A necessidade de conter os abusos do capitalismo trouxe, como consequência, a positivação de normas de caráter social para regular a situação. Como explica Vidal Serrano Nunes Júnior a positivação de direitos sociais tem papel importante na contenção da agressão que o capitalismo gerava às relações humanas.

Assim, ainda hoje, com a Constituição de 1988, identifica-se no rol de normas de direito econômico um aparato de normas de caráter social, com objetivo de conter o poder econômico. Além de serem encontradas normas marcadas pelo caráter social no título da Ordem Econômica, há um título próprio para Ordem Social (Título VII - “Da Ordem Social”). Esta separação, contudo, não deve levar ao entendimento de que essas duas ordens independem uma da outra. Adota-se o postulado da unidade da Constituição para interpretação das normas constitucionais. Por isso, as normas constitucionais devem ser compreendidas em sua totalidade e não de forma isolada.

Quando a Constituição, em seu art.170, define a livre iniciativa e a propriedade privada como valores da ordem econômica, firma como modelo econômico adotado pelo Brasil, o capitalismo. Contudo, não se trata de puro capitalismo. Como apontado, o constituinte albergou outras normas de caráter social como princípios orientadores da ordem econômica, como é o caso da função social da propriedade, da defesa do consumidor, da defesa do meio ambiente, da redução das desigualdades regionais e sociais e busca pelo pleno emprego.

Esse caráter social dado à ordem econômica, leva-nos a afirmar que o modelo econômico adotado pelo Brasil é, na verdade, um modelo de "liberalismo social". A respeito, explica José Afonso da Silva que:

\footnotetext{
"Vimos já que o nosso sistema é fundamentalmente o da propriedade privada dos meios de produção - o que revela ser basicamente capitalista -, que a vigente Constituição tenta civilizar, buscando criar, no mínimo, um Capitalismo social, se é que isso seja possível por meio da estruturação de uma ordem social intensamente preocupada com a justiça social e a dignidade humana." (SILVA, 2005. p. 712.)
}

Verifica-se com o influxo de normas de caráter social que a preocupação precípua deixa de ser apenas o lucro e passa a ser o homem. O próprio “caput” do art.170 da Constituição de 1988 assinala que a ordem econômica deve ser fundada na valorização do trabalho humano e na livre iniciativa, tendo por fim assegurar a todos existência digna, conforme os ditames da justiça social, observados os princípios da ordem econômica. 
Neste específico estudo, destaca-se o princípio do meio ambiente como valor a orientar o desenvolvimento urbanístico sustentável para proteção do direito à moradia.

Segundo Manuel Gonçalvez Ferreira Filho, a proteção ao meio ambiente é, dentro dessa sistemática econômica e social, princípio limitativo da atividade econômica, fruto do "ar do tempo". (FERREIRA FILHO, 2011, p. 94)

Para Robert Alexy, os princípios são mandamentos de otimização, o que significa dizer que podem ser satisfeitos em graus variados de acordo com as condições fáticas e jurídicas. (ALEXY, 2008, p.90) Sendo que, “o âmbito das possibilidades jurídicas é determinado pelos princípios e regras colidentes." (ALEXY, 2008, p.90) Parece, assim, que o princípio do meio ambiente deverá encontrar possibilidades fáticas e jurídicas para sua concretização.

Quanto à possibilidade jurídica, nota-se que o meio ambiente traz limites à atividade econômica, no sentido de ditar para esta o seu respeito, que muitas vezes exige abrir mão de parcela de seu lucro. Outrossim, torna-se indispensável a ponderação entre os valores da iniciativa privada, da propriedade e do meio ambiente, em que seu resultado deve ter por finalidade a máxima efetividade destes princípios.

Por outro lado, quanto às possibilidades fáticas de implementação da proteção ao meio ambiente constatam-se dificuldades decorrentes de situações de pouco desenvolvimento, como: a falta de educação, a falta de conscientização das pessoas no uso dos recursos naturais, a insuficiente fiscalização das áreas de proteção, a falta de planejamento racional das ações, o combate à pobreza, a falta de cooperação entre todos, dentre outras situações que, na verdade, demandam uma política ambiental.

Desperta-se com o exposto que o desafio é saber em que medida pode-se concretizar o princípio do meio ambiente dentro de um desenvolvimento sustentável, em específico, para a garantia do direito à moradia em um meio saudável. E, com isso, destacar a importância deste princípio para a sociedade.

\subsection{O desenvolvimento na Constituição de 1988}

A palavra "desenvolvimento" na Constituição aparece 69 vezes. Já no preâmbulo da Constituição Brasileira, a Assembleia Nacional Constituinte assegurou o desenvolvimento. 
Desde logo, também, em seu artigo $3^{\circ}$, inciso II, assegurou como objetivo da República Federativa do Brasil, o desenvolvimento nacional. Trata-se de um dispositivo normativo que ao lado do reconhecimento de que a sociedade modifica-se frequentemente, indica um futuro de progresso.

Esse desenvolvimento nacional que se inscreve como objetivo fundamental do Estado brasileiro quer, portanto, que a sociedade evolua no sentido de construir uma sociedade livre, justa e solidária. O sistema de normas constitucionais impõe uma relação entre as normas que não pode ser esquecida e que, portanto, essas devem ser condicionadas umas às outras.

Assim, uma primeira leitura do dispositivo constitucional pode levar a entender que se trata apenas de uma evolução econômica, tencionada, fundamentalmente, pelo lucro. Ocorre que a expressão desenvolvimento nacional é mais ampla do que sua consideração econômica. Dentro das disposições constitucionais brasileiras encontra-se atrelada aos dispositivos prescritos pelos fundamentos constitucionais, pelos direitos sociais, bem como pela ordem social.

Coloca Gilberto Bercovici a respeito que:

“(...)o desenvolvimento é uma mudança qualitativa, não apenas quantitativa,
englobando, assim, a idéia de crescimento e superando-a. Feita esta distinção
essencial, podemos adotar aqui o conceito de desenvolvimento exposto por Fábio
Konder Comparato: "De qualquer modo, já se estabeleceu um razoável consenso no
sentido de que o desenvolvimento é um processo de longo prazo, induzido por
políticas públicas ou programas de ação governamental em três campos interligados:
econômico, social e político. O elemento econômico consiste no crescimento
endógeno sustentado da produção de bens e serviços. Endógeno, porque fundado nos
fatores internos de produção e não, portanto, de modo predominante, em recursos
advindos do exterior. Crescimento sustentado, porque não obtido com a destruição
dos bens insubstituíveis, constituintes do ecossistema. O elemento social do processo
desenvolvimentista é a aquisição da progressiva igualdade de condições básicas de
vida, isto é, a realização, para todo povo, dos direitos humanos de caráter econômico,
social e cultural, como o direito ao trabalho, o direito à educação em todos os níveis,
o direito à seguridade social (saúde, previdência e assistência social), o direito à
habitação e o direito de fruição dos bens culturais. Enfim, o desenvolvimento integral
comporta, necessariamente, um elemento político, que é a chave da abóbada de todo
o processo: a realização da vida democrática, isto é, a efetiva assunção, pelo povo, do
seu papel de sujeito político, fonte legitimadora de todo poder e destinatário do seu
exercício.” (BERCOVICI, 2005. p.108)

Dessa forma, considerando a intenção constitucional de construir um Estado Democrático de Direito, o objetivo de progresso deve estar atrelado às questões de garantia da dignidade da pessoa humana. Portanto, ao lado do desenvolvimento econômico, pretende-se assegurar ao ser humano questões mínimas, como a educação, a saúde, o trabalho, a moradia, o lazer, a segurança, a previdência social, dentre outros que se encontram expressamente no artigo $6^{\circ}$ da Constituição. 
Além disso, é preciso ponderar a respeito do modelo de desenvolvimento que se vem empregando, já que não se pode mais negar o esfacelamento do meio ambiente. Consequências como o aquecimento global demonstram que o homem deve modificar sua concepção de desenvolvimento para construção de um homem mais responsável.

Resulta, então, que o desenvolvimento propugna por condições melhores de vida para todos e que dele deve emergir, através das políticas econômicas, valores sociais e ambientais, indispensáveis para uma vida dita feliz e harmônica com o seu habitat.

\subsection{A sustentabilidade como valor constitucional}

A defesa do meio ambiente é uma novidade da Constituição de 1988. Além de ter sido positivada como princípio conformador da ordem econômica (art.170, inc.VI), foi lhe dedicado o Capítulo VI, no Título da Ordem Social. Portanto, a partir do art.225 da Constituição, trouxe para o plano constitucional a necessidade de atentar para a proteção do meio ambiente ao dispor que todos têm direito ao meio ambiente ecologicamente equilibrado, bem de uso comum do povo e essencial à sadia qualidade de vida, impondo-se ao Poder Público e à coletividade o dever de defendê-lo e preservá-lo para as presentes e futuras gerações.

A respeito de sua positivação, explica Celso Ribeiro Bastos que pode ser "devido a uma maior conscientização dos homens com relação à importância que tem para a humanidade a utilização adequada de todos os bens que oferece a natureza." (BASTOS, 2003, p. 156)

A implicação da positivação da defesa do meio ambiente diz respeito ao modo de conduzir as atividades econômicas que, não mais, podem deixar de se atentarem para este bem de uso comum do povo e essencial a vida.

Neste sentido, pode-se dizer que há uma mudança no modo de desenvolvimento econômico a partir da inserção da defesa do meio ambiente na sistemática constitucional. Ocorre que, como acertadamente coloca André Ramos Tavares: “nem o desenvolvimento há de ser impedido pela proteção ambiental, nem o meio ambiente poderá ser desconsiderado pelo desenvolvimento econômico.” (TAVARES, 2003. p.196)

Inclusive, com a alteração dada ao inc.VI do art.170 da Constituição, pela Emenda Constitucional $\mathrm{n}^{\circ} .42$, de 19 de dezembro de 2003, o princípio de proteção ambiental passa a dispor que a ordem econômica deve observar a defesa do meio ambiente, inclusive mediante tratamento diferenciado conforme o impacto ambiental dos produtos e serviços e de seus processos de elaboração e prestação. 
Essa proteção ainda vai além, já que é possível falar, também, em uma dimensão social da sustentabilidade. Isso quer dizer que se deve levar em conta os direitos assegurados constitucionalmente, como o direito à moradia, para a implementação de um desenvolvimento urbanístico sustentável. ${ }^{13}$ A respeito da sustentabilidade social, Juarez Freitas aponta que:

“(...) comprovadamente, as sociedade equitativas, não as mais ricas e assimétricas, são aquelas percebidas como as mais aptas a produzir bem-estar. Em suma, a sustentabilidade, na sua dimensão social, reclama:

(a) A incremento da equidade intra e intergeracional;

(b) Condições propícias ao florescimento virtuoso das potencialidades humanas, com educação de qualidade para o convívio; e

(c) Por último, mas não menos importante, o engajamento na causa do desenvolvimento que perdura e faz a sociedade mais apta a sobreviver, a longo prazo, com dignidade e respeito à dignidade dos demais seres vivos." (FREITAS, 2012, p.5960)

Com isso, verifica-se que a proteção do meio ambiente é salutar. Deve-se buscar a maior efetividade destes dispositivos, com consciência de que são indispensáveis para uma vida digna do homem, tendo em vista a urbanização com o objetivo de proteger o direito à moradia em um meio ambiente saudável.

\subsection{O desenvolvimento sustentável como princípio na Constituição Brasileira}

Desenvolvimento sustentável significa compatibilizar as atividades econômicas com o meio ambiente. No Brasil, não há utilização expressa da expressão "desenvolvimento sustentável", encontra-se implicitamente a partir dos arts.170, inc.VI c/c art.225 da Constituição.

Desenvolvimento, segundo Gilberto Bercovici, "é uma mudança qualitativa, não apenas quantitativa" (BERCOVICI, 2005, p.108). O autor, utilizando-se das palavras de Fábio Konder Comparato, explica que "o desenvolvimento é um processo de longo prazo, induzido por políticas públicas ou programas de ação governamental em três campos interligados: econômico, social e político" (BERCOVICI, 2005, p.108). Sustentabilidade, por sua vez, é qualidade do que é sustentável, ou seja, é a capacidade de se manter mais ou menos constante, ou estável, por longo período. (FERREIRA, 1999, p.1910). Nesse sentido, explica Maria Luiza Machado Granziera que: “A expressão Desenvolvimento Sustentável tem a ver com o futuro.

\footnotetext{
${ }^{13}$ Diz o autor que: “(...) na dimensão social da sustentabilidade, abrigam-se os direitos fundamentais sociais, que requerem os correspondentes programas relacionados à universalização, com eficiência e eficácia, sob pena de o modelo de governança (pública e privada) ser autofágico e, numa palavra, insustentável. (...) O direito à moradia, por sua vez, exige a regularização fundiária e justifica, observados os pressupostos, o direito à concessão de uso de bem público.” (FREITAS, 2012, p.59)
} 
As atividades humanas desenvolvidas em certo momento devem considerar, à luz da disponibilidade dos recursos naturais utilizados, a possibilidade de manter-se ao longo do tempo, para as gerações futuras" (GRANZIERA, 2011, p.57).

Apesar da sua importância, o desenvolvimento sustentável nem sempre foi visto como algo possível de ser concretizado. Prevaleceu, durante muito tempo, o entendimento de não serem compatíveis as ideias de desenvolvimento social, que pressupõe avanços econômicos, e a proteção ao meio ambiente. Assim, apenas recentemente esta preocupação vem ganhando espaço no cenário econômico dos países.

O desenvolvimento sustentável constitui norma-princípio no ordenamento brasileiro e, por isso, segundo Celso Antônio Bandeira de Mello, "mandamento nuclear de um sistema" (MELLO, 2004, p. 841/842).

Portanto, como princípio, a defesa do meio ambiente busca sua maior concretização possível. Dita para economia o dever de desenvolver suas atividades com o mínimo de degradação ambiental possível. Pretende-se uma convivência harmônica entre economia e o meio ambiente. Explica Maria Luiza Machado Graziera que: "Para assegurar o cumprimento desse princípio, deve haver mecanismos institucionais de controle das atividades, para aferir se as normas previstas na legislação em vigor, concernentes à proteção do meio ambiente, estão sendo corretamente observadas pelos empreendedores" (GRANZIERA, 2011, p.60).

Dessa forma, há necessidade de maior conscientização no reconhecimento de que os recursos naturais são finitos e que, por isso, impõem uma economia planejada para sua proteção. Contudo, não se pretende que a proteção do meio ambiente impeça o desenvolvimento e, sim, que este desenvolvimento erga-se sobre os pilares da defesa do meio ambiente. Como salienta Celso Antonio Pacheco Fiorillo:

\footnotetext{
"Devemos lembrar que a ideia principal é assegurar existência digna, através de uma vida com qualidade. Com isso, o princípio não objetiva impedir o desenvolvimento econômico. Sabemos que a atividade econômica, na maioria das vezes, representa alguma degradação ambiental. Todavia, o que se procura é minimizá-la, pois pensar de forma contrária significa dizer que nenhuma indústria que venha a deteriorar o meio ambiente poderá ser instalada, e não é essa a concepção apreendida do texto. O correto é que as atividades sejam desenvolvidas lançando-se mão dos instrumentos existentes adequados para a menor degradação possível." (FIORILLO, 2004. p.27.)
}

Este princípio reclama além da preocupação ambiental, preocupações sociais e econômicas. Almeja uma vida com dignidade e, também, o progresso. O compromisso de um desenvolvimento sustentável, que deve ser assumido pelas presentes gerações com as gerações 
futuras. Protege as sociedades para que estas se ergam sobre fundamentos indispensáveis para sua própria sobrevivência.

Aponta Steiner, que o Brasil é um dos poucos países que dispensam atenção aos três setores fundamentais do desenvolvimento sustentável: o social, o econômico e o ambiental (STEINER, 2012, p.1).

Acerca do tema, coadunado com o que foi dito, entende o Supremo Tribunal Federal que se deve buscar um equilíbrio entre as exigências da economia e as do meio ambiente. Tal entendimento é encontrado na ação direta de inconstitucionalidade n.3540, expresso pelo Ministro Celso de Mello, onde afirma o caráter solidário do direito ambiental e sua importância para direcionar o desenvolvimento sustentável.

\section{A PROTEÇÃO DO DIREITO À MORADIA SOB OS INFLUXOS DO PROCESSO DE URBANIZAÇÃO E O DESENVOLVIMENTO URBANÍSTICO SUSTENTÁVEL DA CIDADE DE SÃO PAULO}

\subsection{O processo de urbanização na cidade de São Paulo}

O processo de urbanização na capital paulista, bem como de sua região metropolitana ocorreu de forma mais significativa na década de 1950, sendo suas áreas mais distantes ocupadas a partir da década de 1960, saindo para além das fronteiras centrais da cidade e ocupando áreas periféricas, de várzeas e encostas, onde a terra era desvalorizada e, por este motivo, não pretendida pelo mercado imobiliário da época, resultando em inúmeros problemas para a cidade e para a população residente destas áreas até os tempos atuais.

Exemplo dos resultados desta ocupação sem planejamento são as inundações constantes, em épocas de chuvas, das áreas ribeirinhas ocupadas em razão da proximidade com os postos de trabalho e dos serviços públicos, às margens dos rios Tietê, Tamanduateí e Pinheiros (FREITAS, 2011, p. 225-226); ou ainda, o caso da Baixada do Glicério como exemplo histórico do modelo de ocupação do solo urbano na cidade de São Paulo, seguida pela ocupação, na década de 1990, das áreas localizadas às margens das represas Billings e Guarapiranga ao Sul, a encosta da Serra da Cantareira ao Norte e das várzeas localizadas nos extremos leste e oeste da cidade (FREITAS, 2011, p. 226-227).

Dessa forma, nota-se que a falta de planejamento para absorver os novos habitantes das cidades e a ocupação desordenada de áreas sem infraestrutura adequada para o 
estabelecimento de moradias causam reflexos até hoje na qualidade de vida da população paulistana.

Não se pode, ainda, ignorar a existência de favelas ${ }^{14}$ na região urbana da cidade de São Paulo, resultante do processo de urbanização, anteriormente, exposto, e que surgiram na década de 1940 (TASCHNER, 2002. p. 04.) e se desenvolveram em larga escala na década de 1970 (BÓGUS, 1991. p. 50) às margens da cidade, formando um cinturão que cresceu desorganizadamente em locais de difícil acesso e áreas de risco pelo constante temor dos alagamentos ou desmoronamentos, além da falta de infraestrutura básica.

Este processo de favelização, isto é, do crescimento do número de favelas e seus habitantes na cidade de São Paulo e Região Metropolitana tem tido um aumento significativo nas últimas décadas, principalmente em relação ao crescimento da população do município, demonstrando que o problema cresce de forma exponencial e preocupante, principalmente no que se refere ao meio ambiente e ao Princípio da Cidade Sustentável.

Um estudo publicado por pesquisadores na Revista Brasileira de Estudos Urbanos e Regionais, na década passada, sobre a favelização na cidade de São Paulo e Região Metropolitana, apontaram o seguinte:

A população favelada de São Paulo tem crescido a taxas superiores às da
população do município, o que equivale a dizer que sua proporção se elevou
na última década. Os dados de setores subnormais, embora subestimados,
apontam para um importante crescimento da população favelada entre 1991 e
2000 , numa taxa de $3,7 \%$ ao ano, quatro vezes superior à média da metrópole.
Nossa estimativa indica uma taxa mais reduzida - 2,97\% a.a., mas muito
superior à taxa de crescimento da população total - 0,9\% a.a. Esse crescimento
se deu principalmente pela elevação da área total de favelas (que cresceu $24 \%$
na década), mas também pelo aumento da densidade média das favelas (que
subiu de 360 para 380 habitantes por hectare - $6 \%$ de aumento). Os dados
apontam, portanto, para um importante processo de favelização no município
de São Paulo na década de 1990. (MARQUES; TORRES; SARAIVA, 2003.
p.25.)

Em 2014, a Secretaria da Habitação indicava que na cidade de São Paulo existam, aproximadamente, 1643 favelas $^{15}$, ocupando uma área de 24 quilômetros quadrados, distribuídas por todas as cinco regiões da cidade, números que por si só demonstram a dimensão do problema existente na cidade paulistana e que pode ainda piorar com a atual crise econômica

\footnotetext{
${ }^{14}$ Segundo definição da Secretaria Municipal da Habitação e Desenvolvimento Urbano, tanto as definições das pesquisas da Prefeitura Municipal (1973, 1975, 1987 e 1993), como a de 1980 do IPT-Fupam consideram favela "todo o conjunto de unidades domiciliares constituídas de madeira, zinco, lata, papelão ou alvenaria, em geral distribuídas desorganizadamente em terrenos cuja propriedade individual do lote não é legalizada para aqueles que os ocupam". (TASCHNER, 2001. p. 13.)

${ }^{15}$ Informações obtidas no site: http://www.habisp.inf.br/principal/busca?tipo=favela . Acesso em 12.06.2014.
} 
enfrentada pelo País, merecendo atenção dos órgãos públicos no intuito de iniciar uma reversão desse processo.

4.2 Os problemas decorrentes da ocupação irregular do solo urbano e do processo de urbanização da cidade de São Paulo

A ocupação desordenada do solo na cidade de São Paulo em razão do processo de urbanização sem planejamento resultou em inúmeros problemas para os habitantes paulistanos. Dentre as razões para os problemas resultantes dos impactos ambientais experimentados pela cidade, atualmente, temos a impermeabilização do solo pelo asfaltamento de ruas e a concretagem das construções ${ }^{16}$; a destruição de matas ciliares ${ }^{17}$; a contaminação do solo urbano por resíduos químicos ${ }^{1819}$; a instalação elétrica realizada de forma inadequada em áreas de favelas que resultam em incêndios; a queima de resíduos sólidos nas áreas de lixões que aumentam a poluição do ar causando problemas diversos de saúde; o descarte de lixo em áreas inapropriadas da cidade que servem de abrigo para a reprodução dos vetores de inúmeras doenças epidêmicas, a ocupação de áreas ribeirinhas e de mananciais que comprometem e degradam as fontes de água potável, dentre outros que os habitantes de São Paulo conhecem bem e experimentam seus efeitos todos os dias.

Nesse sentido, o professor Pedro Jacobi da faculdade de educação da USP e pesquisador do CEDEC - Centro de Estudos e de Cultura Contemporânea explica que:

Os problemas ambientais na cidade de São Paulo são principalmente um efeito da urbanização sobre o ecossistema, decorrente da utilização inadequada dos recursos físicos como a água. Um fator significativo de degradação ambiental,

\footnotetext{
${ }^{16}$ A impermeabilização do solo dificulta que a água da chuva seja absorvida pelo solo, causando enchentes em áreas urbanas, principalmente em períodos de aumento das precipitações.

17 Segundo o relatório final do Observatório de Clima e Saúde, da Fiocruz, ligada ao Ministério da Saúde, o desmatamento, a ocupação e urbanização desordenada, somados a condições sanitárias de higiene e moradia inadequadas configuram um quadro preocupante para a incidência de vetores, principalmente considerando que, mesmo que o clima não se altere de forma significativa, as populações humanas estão aumentando e a densidade populacional pode exacerbar as diferenças que determinam o quadro social onde ocorrem os agravos de saúde. O desmatamento pode influenciar diretamente no aparecimento de casos de febre amarela - o vetor Haemagogus janthinomys na mata atlântica, $\mathrm{Hg}$. capricornii no cerrado e $\mathrm{Hg}$.leucocelenus. http://www.climasaude.icict.fiocruz.br/temas/relatoriooficinavetores.pdf. Acesso em 20.09.2016.

${ }^{18}$ De acordo com o Decreto Municipal no 51.436/2010, que regulamenta a Lei Municipal no 15.098/2010, compete à Secretaria Municipal do Verde e do Meio Ambiente - SVMA a publicação do Relatório de Áreas Contaminadas do Município. O relatório de áreas contaminadas divulgada pela Prefeitura de São Paulo em 2016 aponta que existem atualmente 468 áreas contaminadas, sendo 26 áreas públicas. http://www.prefeitura.sp.gov.br/cidade/secretarias/upload/23\%20GTAC_Jul_2016.pdf Acesso em 24.09.2016.

${ }^{19}$ Segundo definição obtida pelo site da prefeitura de São Paulo, Área Contaminada é aquela considerada como: área, terreno, local, instalação, edificação ou benfeitoria que contenha quantidades ou concentrações de matéria em condições que causem ou possam causar danos à saúde humana, ao meio ambiente ou a outro bem a proteger.
} 
ao lado da contaminação da água, decorre da exiguidade da rede de esgotos, assim como do déficit de sistemas de tratamento dos esgotos e águas servidas e da descarga ainda muito pouco controlada dos dejetos tóxicos industriais e comerciais. (...) A deterioração ambiental resulta da precariedade dos serviços e da omissão do Poder Público na proteção/prevenção das condições de vida da população, mas também é reflexo do descuido e omissão dos próprios moradores de bairros carentes de infra-estrutura no tocante ao despejo de resíduos sólidos em locais públicos desrespeitando o coletivo local. (JACOBI, Pedro. 1993. p.50)

Dessa forma, depreende-se que muitos dos problemas que afligem os habitantes da cidade estão intimamente relacionados com a urbanização desenfreada e sem planejamento que impacta diretamente e negativamente no direito social à moradia de seus habitantes, bem como no desenvolvimento sustentável da cidade de São Paulo.

\section{CONCLUSÕES}

É possível afirmar que o processo de urbanização desperta problemas sérios na proteção do direito à moradia, especialmente a partir do olhar do desenvolvimento sustentável social.

O Estatuto da Cidade completou no último mês de julho, quinze anos desde que entrou em vigor, e os resultados práticos, infelizmente, foram pouco percebidos pelos seus destinatários, certo de que, talvez, não seja a falta de instrumentos, mas sim a deficiente implementação deles pelo poder público que, por sua vez, possa ter relação com a falta de recursos para a consecução dos objetivos preconizados na lei.

Observa-se, ainda, que o cenário atual coloca as cidades brasileiras no caminho oposto ao pretendido pelo legislador do Estatuto, pois a crise econômica agravada pela atual crise política experimentada no Brasil fez crescer o desemprego, resultando na diminuição do poder aquisitivo dos cidadãos e afetando mediata e imediatamente a possibilidade de reversão do processo de favelização resultante, dentre inúmeros fatores, do processo de urbanização ocorrido nas cidades brasileiras no século XX.

A proteção do direito à moradia depende do desenvolvimento sustentável da urbanização, assim, como se verifica que o direito à moradia é imprescindível para a consecução de outros direitos sociais e fundamentais garantidos pela Constituição.

Por fim, afirma-se que se deve caminhar para a concretização do modelo constitucional definido de pretender um desenvolvimento sustentável capaz de proporcionar a moradia com 
dignidade. Os problemas decorrentes da não efetividade das normas indicam consequências sérias para todos os habitantes da região, a se verificar São Paulo como exemplo.

\section{REFERÊNCIAS}

ALEXY, Robert. Teoria dos Direitos Fundamentais. Tradução de Virgílio Afonso da Silva. $5^{a}$ ed. São Paulo: Malheiros, 2008;

BASTOS, Celso Ribeiro. Curso de Direito Econômico. São Paulo: Celso Bastos editora, 2003;

BERCOVICI, Gilberto. Constituição Econômica e Desenvolvimento - uma leitura a partir da Constituição de 1988. São Paulo: Malheiros, 2005;

BÓGUS, Lúcia Maria Machado. Direito à Cidade e Segregação Espacial. 1991. http://www.seade.gov.br/produtos/spp/v05n02/v05n02_08.pdf Acesso em 04.05.2013;

CARVAlHO FILHO, José dos Santos. Comentários ao Estatuto da Cidade. $5^{\text {a }}$ edição revista, ampliada e atualizada. São Paulo: Atlas, 2013;

FERREIRA. Aurélio Buarque de Holanda. Novo Aurélio - o dicionário da língua portuguesa. Século XXI. Ed.: Nova Fronteira;

FERREIRA FILHO. Manoel Gonçalvez. A Constituição "Econômica" de 1988. In: MARTINS FILHO, Ives Gandra da Silva; MEYER-PFLUG, Samantha Ribeiro (Coordenadores). A Intervenção do Estado no Domínio Econômico: condições e limites Homenagem ao Prof. Ney Prado. Ed.: LTr;

FREITAS, José Carlos. Ocupações Irregulares - Riscos sociais decorrentes da falta de saneamento inTemas de Direito Urbanístico 6 - Áreas de Risco. São Paulo: Imprensa Oficial do estado de São Paulo: Ministério do Estado de São Paulo, 2011;

FREITAS, Juarez. Sustentabilidade - Direito ao futuro. Belo Horizonto: Editora Fórum, $2^{\mathrm{a}}$ edição, 2012;

FIORILlo, Celso Antonio Pacheco. Curso de Direito Ambiental Brasileiro. $5^{\text {a ed. São }}$ Paulo: Saraiva, 2004;

GRANZIERA, Maria Luiza Machado. Direito Ambiental. São Paulo: Atlas, 2011;

JACOBI, Pedro. A percepção dos problemas ambientais urbanos em São Paulo. Lua Nova [online]. 1993, n.31, pp.47-56.

MARICATO, Ermínia. Metrópole, Legislação e Desigualdade In Estudos Avançados no 48, 2003; 
MARQUES, Eduardo; TORRES, Haroldo da Gama e SARAIVA, Camila. Favelas no Município de São Paulo: Estimativas de População para os anos de 1991, 1996 e 2000. in Revista Brasileira de Estudos Urbanos e Regionais, Vol. 5, N1: 2003;

MELlo, Celso Antônio Bandeira de. Curso de Direito Administrativo. São Paulo: Malheiros, 2004;

SAULE, Nelson Junior. A Proteção Jurídica da Moradia nos Assentamentos Irregulares. Porto Alegre: Sergio Antonio Fabris Editor, 2004;

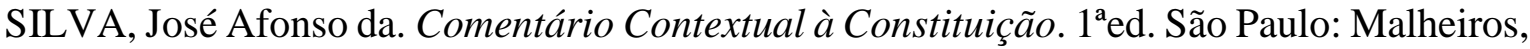
2005

STEINER, Achim. "É hora de um acordo global”. Entrevista concedida a Revista Veja, em 15 de fevereiro de 2012;

TASCHNER, Suzana Pasternak. Favelas em São Paulo - Censos, Consensos e Contrasensos. 2001. http://revistas.pucsp.br/index.php/metropole/article/viewFile/9294/6898 Acesso em 04.05.2013;

TASCHNER, Suzana Pasternak. Espaço e População nas Favelas de São Paulo. 2002. .http://www.abep.nepo.unicamp.br/docs/anais/pdf/2002/GT_MA_ST21_pasternak_texto.pdf Acesso em 04.05.2013;

TAVARES, André Ramos. Direito Constitucional Econômico. São Paulo: Método, 2003;

TUTIKIAN, Cláudia Fonseca. Propriedade Imobiliária e o Registro de Imóveis: Perspectiva Histórica, Econômica, Social e Jurídica. São Paulo: Quartier Latin, 2011. 